\title{
Moodle System one of the way to Monitoring Competence of Future Teachers of Music art.
}

\author{
OLHA CHURIKOVA-KUSHNIR ${ }^{1}$, ZOYA SOFRONII ${ }^{1}$, VADYM LISOVYI ${ }^{1}$, HEORHII \\ POSTEVKA $^{1}$, LILIYA NIEMTSOVA $^{1}$ \\ ${ }^{1}$ Department of Music, Faculty of Pedagogy, Psychology and Social Work, Yuriy Fedkovych \\ Chernivtsi National University, UKRAINE
}

\begin{abstract}
The article are given the scientific and methodological conditions for the production and progress of distance learning courses for future teachers of music through the competencebased, system, action approaches . The author identifies the components that are formed on the basis of the content of the course are and portion of the structure of the competence hierarchy of future music teacher. Materials of research are founded on the experience of education in the course of distance learning of Basic Musical Instrument (piano). The study consi ders the principal components of development and design of a distance learning course, including theoretical, $p$ ractical, individual work, and control. The author grounds the specifics methods of distance learning for future teachers of music, in specific their instrumental training and the effectiveness of this training, differentiating the following main methods: of collecting information and using technologies of communication, such us multime dia and method of project. The criteria for control of information and skills were developed. The research was portion of educational experiment involving 52 bachelor students, Music Specialization. According to the result s of the study, the study of the subject Basic Musical Instrument (Piano) using the Moodle learning environmen $\mathrm{t}$ contains a number of advantages, which are primarily manifested in higher assessment results of students' lear ning. The motivational, musical instrumental and cognitive abilities of these students were approximately $10 \%$ higher than students who studied according to traditional methods. The opinion characterize the results of implementation and effectiveness of experimental study on the use of distance learning courses for the progress of instrumental performance competence of future teachers of music. The influence of different methods of distance learning on learner performance is also determined.
\end{abstract}

Key-Words: - Professional competence, music teachers in primary school, academic performance monitoring, Moodle system, distance learning.

Received: December 27, 2020. Revised: July 14, 2021. Accepted: July 25, 2021. Published: August 8, 2021.

\section{Introduction}

Monitoring the professional competence of future music teachers by means of modern Internet technologies is an urgent problem of the modern educational space. Each one of characteristic features of modern art education is fixed modernizing in accordance with the requirements of the information space, which is actively developing in the university programs, as well as the communication educational environment [1]. The active development and use of electronic educational resources, information and multimedia sources, electronic textbooks and manuals, educational software tools increasingly become typical phenomena of art education.

Distance learning tools are also being gradually involved to education and distance learning courses for future music teachers in order to study historical theory and methodological art subjects. Therefore, it is necessary for modern art pedagogy to discover new forms and methods of teaching different types of art that would be effective in the context of distance learning.

Scholars emphasize this importance of using information and communication technologies (ICT) in music education to transmute it into a highly artistic high-tech process. New software that organically combines traditional pedagogical tools of music education, and ICT capabilities are actively developing and authorizing the use of computers as a professional tool for future music teachers.

Informatization of the artistic component in the professional training of future teachers of music has become an important part of the learning process, as evidenced by numerous scientific and pedagogical studies. 
As for development of pedagogical, at present it's required the basics of organization of professional action of pedagogical staff of higher educational institutions, focusing mainly on the formation of competencies and creating conditions for the development of relevant professional competencies in students of creative specialties of pedagogy. The content, organization, structure and methodology of development of communicative competence of future specialists in creative specialties of pedagogy require updating [2].

Some researchers look the urgency of forming the professional competence of future teachers of music on the principles of an interdisciplinary procedure. In particular, it is a method of modelling, which is based on the interdisciplinarity principle [3].

As for the introduction of distance learning methods, including through the Moodle system, higher educational institutions in progressive countries are developing rapidly [4]. Thus, they indicate significant progress in learning through the Moodle distance learning system. However, more attention is paid to this practice in developed countries, while these figures are much lower in developing countries. At the same time, the outbreak of COVID-19 has forced to social distancing. Therefore, higher educational institutions will be able to support their authority and educational achievements only when they actively use distance learning tools [5].

In view of the above, the important objectives of the study are:

1) development of a distance course Basic Musical Instrument (piano);

2) determination of methods of realization of this course on the basis of the Moodle system of learning;

3) introduction of an online course among students during one semester;

4) analysis of the obtained results of the students of the experimental group and comparison of these results with the academic performance of students who studied offline.

\section{Literature review}

E-learning looks both like the completion and continuation of traditional education [6]. At the same time, education becomes better, it can be provided by highly qualified personnel, such education is available to more people thanks to elearning. Moreover, the cost is lower. Accordingly, e-learning is becoming more beneficial than the traditional education system [7].
In recent periods, learning in online changed the educational with the emergence of new ways of learning. This fact, together with recent changes in education policy in Europe, has provoked a change in the provision of learning and a review of the roles that the teachers and students played. For example, there is an emphasis on the need to develop basic and interdisciplinary competencies of teachers and students [8]. Together with recent changes in educational policy in Europe, this fact provoked a change in the provision of learning and a review of the roles teachers and students. For example, there is an emphasis on the need to develop basic and interdisciplinary competencies of teachers and students [8].

In addition, many new subjects have emerged in recent years, as well as new teaching methods, the implementation of which requires the use of information obtained through Internet technology.

In pedagogical science, there are already studies related to the importance of distance learning Internet resources. In particular, Serbian researchers considered differences in students' perceptions of value, quality characteristics in the Moodle learning management system, and also identified the level of student satisfaction with these characteristics [9]. These studies were gender-sensitive, and showed that students of both genders were equally satisfied with the Moodle system in terms of its qualitative characteristics, but there was a difference in the importance that students attached to these characteristics. For example, time for waiting a response, quality of feedback, clarity and quantity of materials, ease of use of websites, variety of cooperation, etc. played a more important role for female students.

American research shows how music teachers, using the capabilities of the Moodle system, have developed a working prototype of a digital portfolio of a music teacher, which would, moreover, comply with the law. The development involved 12 heads of educational institutions of music education. The developed prototype demonstrated a much higher quality of teacher-student cooperation, which affected the growth of student performance [10].

One of the most popular e-learning tools is learning management systems are. For example, Italian research has made significant progress in developing the importance resources that are available to most learning management systems now, including solutions to provide students with personalized support throughout the learning process. Thus, the Italians developed an innovative system of educational content delivery, which was based on the personalization of educational 
experience. In particular, this system integrates Moodle with the LS-Planning platform, which provides an automated sequence of learning material based on existing knowledge and the learning process of students [11]. Italian scholars have also developed a special module that provides some support for the operations of obtaining, analysing and importing training materials from a set of standard repositories of training facilities. In particular, this module is designed to support the teacher at the stage of finding training materials using a keyword-based search system [12].

The problem of using information technology, in particular the Moodle system, in education has been studied on the basis of medical universities [13], as well as mathematical education [14]. In both cases, the researchers emphasize the positive results. Researchers emphasize the benefits of learning foreign languages using the Moodle system and its video sharing tools in linguistic higher educational institutions $[15,16]$. Teachers of higher educational institutions are constantly looking for more effective approaches in teaching English, as well as creating an electronic educational environment that would allow students to access different sources of information [17].

There are studies that address the expectations of Music Art teachers regarding the content of their curricula and compliance with the principles of professional education of teachers in the application of e-learning systems [18].

Researchers identify two popular learning models in the Moodle system: VAK-style learning, which includes visual, auditory, and kinesthetic approaches, and Felder-style, based on global and consistent approaches [19].

The use of e-learning Moodle system significantly affects the change of teaching methods. For example, according to the study by Portuguese researchers [20], most educators used Moodle as a repository for learning materials, as well as a platform to improve their own methods, while the most used resources were file or website links and composing a text page. At the same time, most teachers did not change their teaching practice, but rather adapted the capabilities of Moodle to their pedagogical experience. In general, according to international research, Moodle often becomes a repository of content instead of an interactive environment [21].

Canadian educators have attempted to improve the Moodle learning system by organizing it so that it is flexible and easy to use according to the cognitive features of teachers and students [22].
The problem of informatization of education is also actively studied in the so-called "Third World" countries. For example, Kenyan universities use elearning technologies as a means of conveying the content of a course. However, according to research by Kenyan educators, teachers and students have different views on the ease of use of e-learning systems, and ways to overcome such conflicts are the main task of distance education [23]. Research conducted in higher educational institutions in Nigeria shows that the majority of full-time university professors $(89 \%)$ believe that ICTs are mandatory in the educational process [24].

\section{Materials and methods}

We used a set of theoretical (operational, thematic and final analysis, systematization and generalization) and empirical (conversation, survey, educational experiment, modelling, testing, observation) methods in the process of solving research problems.

At the initial stage of the research we developed a distance course - Basic Musical Instrument (piano), using a simulation method. The main stage of its study and testing were part of an educational experiment in the context of professional training of future music teachers at the Faculty of Primary Education. In particular, the experiment involved 52 bachelor students (Music Specialization). We performed a constant operational analysis during the experiment. This analysis allowed recording the main indicators of the educational process in the context of distance learning, as well as finding out the causes of gaps in students' knowledge and developing algorithms to eliminate these causes.

The thematic analysis was aimed primarily at studying the most important issues in the process of training music teachers, in particular the formation of their competence skills. This analysis allowed us to develop substantive recommendations for arranging the curricular of the distance learning course Basic Musical Instrument (piano) in order to improve its quality.

The final analysis of the introduction of the distance learning course Basic Musical Instrument (piano) provided an average of $10 \%$ higher performance of students during the study of the subject, compared to a similar course, which was taught according to traditional methods.

We determined the initial, intermediate and final quantitative and qualitative results of students' level of the basic competencies of the future music teacher through testing, survey, interviews, and observations during the experiment. 
The main methodological approach used in the study is competence-based one. It helped to study the ways to use distance learning courses, as well as organize the development of productive learning skills in the training of music students, identify a range of distance learning methods for future music teachers to acquire instrumental skills. In terms of the competence-based approach, the emphasis was shifted from the process of scholastic accumulation of the range of theoretical knowledge, skills and abilities provided by the programs and various regulations towards the formation and development of the ability to act, apply individual techniques, and successful professional experience.

In addition to the competence-based approach, an activity approach was used to substantiate the process of forming professional skills of future music teachers through active subject activity. The system approach was also used to study the distance learning course Basic Musical Instrument (piano) in combination with other pedagogical and musical subject as an integral element of the system of professional knowledge of a music teacher.

\section{Results}

\subsection{Basic Musical Instrument (Piano) - review of the Distance Learning Course}

The distance learning course Basic Musical Instrument (piano), as well as the traditional occupation, organically add the professional's training system of future teachers of music, performing the principles of mix learning, and has the following components: 1) practical; 2) theoretical; 3) control; 4) separate work.

The important objectives of the course Basic Musical Instrument (piano) include both those aimed at the formation of theoretical skills and practical skills (see Figure1 for details).
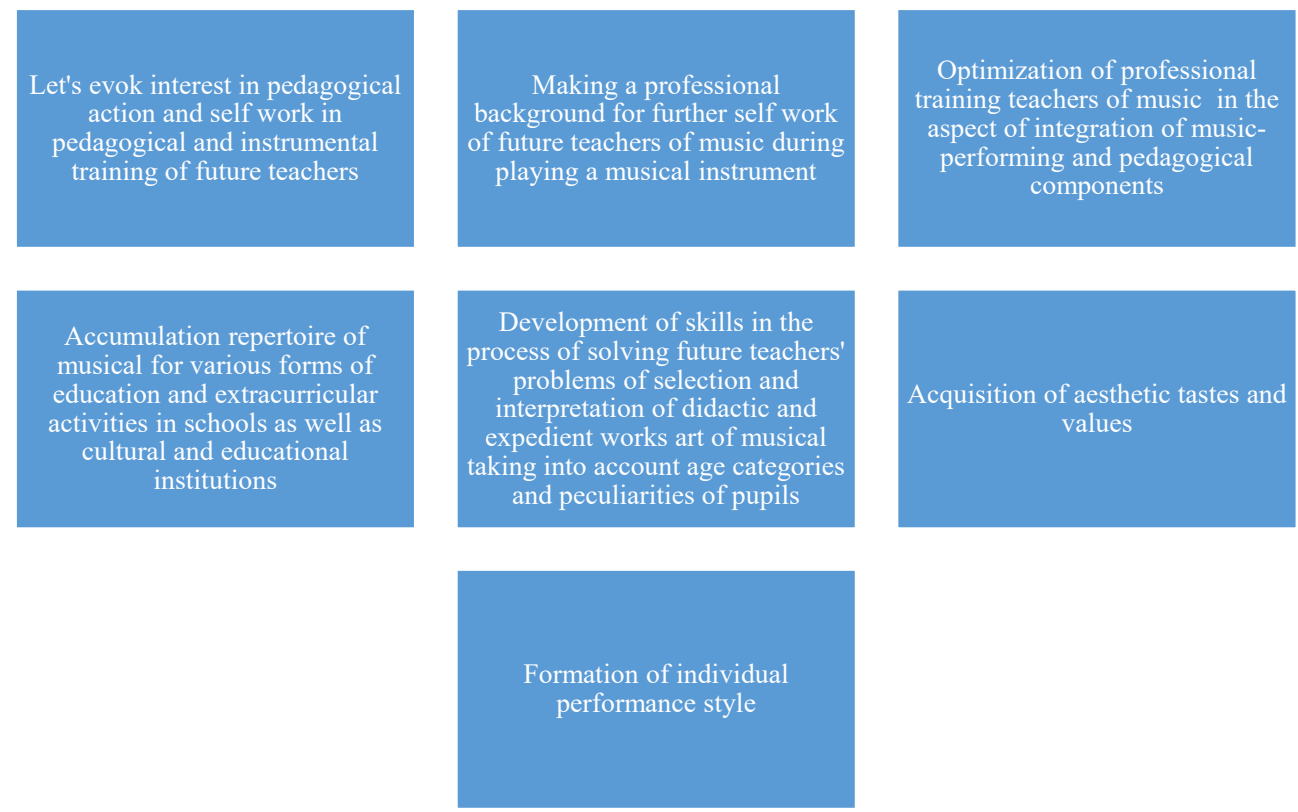

Figure 1. Objectives of the course Basic Musical Instrument (piano)

The expected result course of the distance learning Basic Musical Instrument (piano) was the professional instrumental competence. It provided for free playing a musical instrument (piano), as well as to use it in concert, educational and performance activities; acquired expertise of reading sheet music, transposition, selection of music by ear; mastered methods of teaching to play musical instruments; developed skills of instrumental music selection for students during music lessons and extracurricular activities. The structure of future performance instrumental competencies teachers of music traditionally includes cognitive, operational and motivational components. The content of the course Basic Musical Instrument (piano) have 5 modules, which unite 10 topics (Figure 2).

Basic Musical instrument (piano) became preceded by an facts issue containing widespread records approximately the direction, a discussion board for conversation with students, and a thesaurus for the path (simple ideas and their interpretation). There were assignments for creative initiatives, guidelines for developing e-portfolio, an approximate repertoire, and a listing of advocated literature available for download.

The theoretical component of the direction is aimed at the formation and development of the cognitive factor within the thing of reading devices 
via destiny tune teachers and their acting competence. This thing contained text materials of lectures with displays, diagrams, tables, as well as multimedia factors (audio, video fragments, pictures, reproductions of works of pleasant art, and so forth.). The lecture material is provided in quick and supplemented by means of musical compositions for audition.

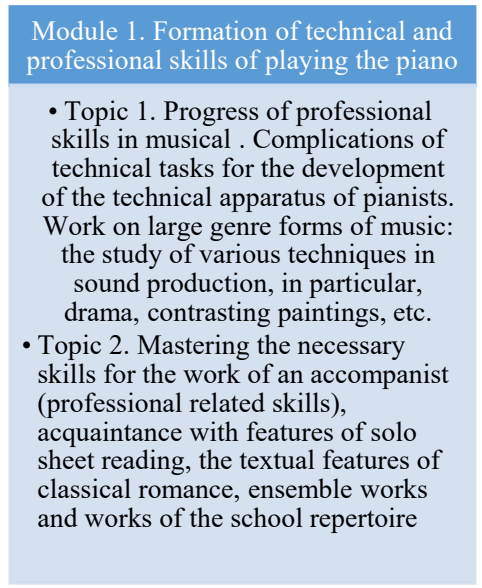

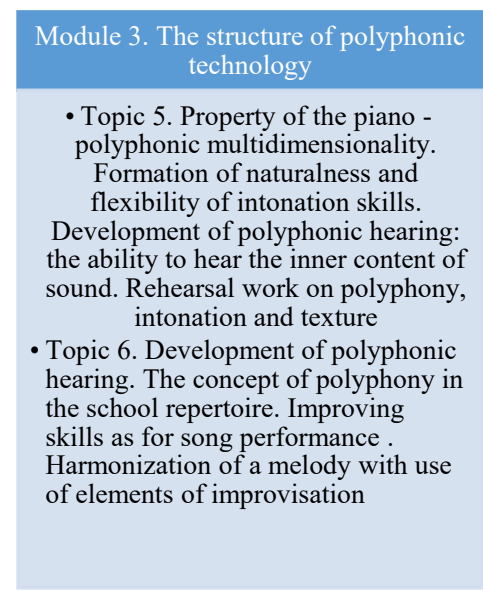

Figure 2. Contents of the course Basic Musical Instrument (piano)

The practical aspect mastering Basic Musical instrument (piano) is geared toward forming the operational constituent of instrumental and performing competence, and contributed to the development of abilities and competencies to pay attention to tune, play a musical tool without difficulty, abilities of studying sheet tune, transposition, choice of tune by ear, musicalanalytical hobby, development of innovative musical thinking.

The factor of impartial paintings contained assignments that required complete solutions thru using net assets, paintings with multimedia sources, their processing each personally and in groups, aimed generally at forming the motivational and fee aspect, instrumental and acting abilities of future music teachers. The manipulate of musical information and instrumental talents received at some stage in the have a look at of the distance direction basic Musical device (piano) became exercised in the form of a test (Moodle getting to know environment affords an opportunity to check understanding of theoretical cloth effectively, in addition to test the level of notion of track by way of ear through tests of various types) with instant effects.

\subsection{The specifics of distance learning methods for future teachers of music in terms of the development of instrumental and acting abilties}

Let's see the technique of involving information and communique technologies, including multimedia. With a view to create a complete image of interpretation and immerse your self in the content of a musical work, you need not else handiest technical excellence, but also professional talents, which rely upon a set of musical expertise, abilities, aesthetic wishes, values and other character traits. The musician must know and systematize musical forms in their ancient improvement, have quite a number understanding about instrumental compositions and musical works of literature (in addition to biographies of composers, records about musical works), understand the troubles of musical aesthetics. We also want to get data about the development of artwork traits and innovative schools, the effect of various factors of the composer's paintings on the spiritual lifestyles of society. In addition, the take a look at of musical and instrumental works includes the use of interdisciplinary links with records, literature, cultural research and various arts (portray, theatre, cinema and choreography). As a consequence, musical performance as an interpretive interest is one of the maximum various sorts of musical pastime, which incorporates a tremendous extent of statistics. Cutting-edge technologies, mainly, multimedia and different computer technologies, significantly facilitate the look for data, and assist to deepen the information of a particular musical phenomenon thru special types of records (textual, graphical, visible - static and dynamic).

The ICTs had been involved within the following areas:

- take a look at of the existence and paintings of composers, inclusive of with the usage of their person works on the net; 
- observe of scientific articles;

- listening to audio files;

- viewing films that provided "immersion in the generation";

- search for musical and acting interpretations of a work achieved by well - known and little-known pianists with a purpose to analyse and evaluate the writer's interpretations;

- advent of personal verbal interpretations of a musical work meant for positive audiences, along with with the use of generalized information from various net resources and conducting a radical analysis of the composer's fashion and his use of musical approach;

- use of online tune libraries;

- involvement of the digital context of multimedia encyclopaedias and other information courses;

- recording the overall performance of a musical composition using a video digital camera or phone for in addition evaluation of the translation of a musical work (independently or with a teacher);

- involvement of visible associations through the search for works of painting and other nice arts, creative analogies that deepen the translation of the content material of a musical composition.

The method of involving data and conversation technologies contributed to the improvement of sure musical and performing competencies:

- development of character musical questioning, mastering the skills of self-presentation and conversation with distinctive audiences;

- introduction of an auditory model of overall performance and interpretation of a musical work;

- development of the capacity to use the media during schooling and significantly examine very own media activity.

In terms of using the venture method, we determined the algorithm of the creative mission, the level of activity of the contributors of this task, which become also a hallmark of readiness and competencies of the future tune trainer to perform and interpret their musical abilties; choice of participants of the artwork and performance mission and the choice of its subject matter; declaration of the problem, motive and dreams of the art mission; figuring out the kind and content of creative and project sports; choice of strategies and approach of task implementation; unbiased appearing and interpretive activity of college students.

Deciding on undertaking topics, students had been offered two sorts: a unmarried-challenge undertaking on basic Musical instrument (piano) (layout and interpretation of sports inside a certain repertoire and assignments in tune classes), and a multidisciplinary mission on the expert situation (practical training on school Repertoire, extra Musical contraptions, records of Musical styles, analysis of Musical Works, etc.). Precise task topics have been agreed with the members of the experimental take a look at.

The facts thing of the distance path presented college students the topics of various content material, taking into consideration the person stage of institution members and their musical tastes. The projects were carried out all through the college year and evaluated by means of teachers at the stage of each modern and very last manage. In addition, students mentioned their projects on the discussion board and despatched meantime and very last reports at the mission and its implementation the usage of the Assignments module.

For example, to enforce the venture harmony of music and portray inside the works of Čiurlionis, a set of students turned into divided into teams:

1) search engineers (fundamental activity - look for statistics about the lifestyles and paintings of Lithuanian composer and artist at the internet, and search for his piano plays finished through distinctive pianists, look for his artwork of the equal name);

2) artwork critics (major interest - analytical: musicology, musical pedagogical and interpretive analysis of certain works via Čiurlionis for piano; advent of analytical schemes; aesthetic and stylistic evaluation of paintings and evaluation of the precept of embodiment of musical expression inside the artist's artwork).

The final degree of the mission harmony of music and painting in the Works of Čiurlionis changed into the interpretation of three musical works of the composer, which were observed with the aid of multimedia visible material, providing artwork with the aid of this author intently associated with his musical works.

The challenge pix from the Exhibition by means of Mussorgsky involved the implementation of the precept of integration of tune and art. The cause of this mission is to discover good integration of tune and art. The cause of this mission is to discover good enough sound, colorings and sunglasses by using students, destiny teachers of song, in addition to a departure from the traditional canons of interpretation of the famous piano cycle by Mussorgsky.

Similarly to the primary mission, two groups have been selected: seek engineers (predominant activity - search for statistics: search for statistics approximately the lifestyles and paintings of Mussorgsky, search for the brightest piano and orchestral interpretations of the collection snap shots 
from the Exhibition, as well as the search for reproductions of works that inspired the composer; art critics; IT specialists (the principle pastime is informational and multimedia assist of interpretations of Mussorgsky's piano cycle, their visualization with the help of computer technologies); performers-interpreters (the primary activity - interpretation of musical performances with brief comments on the content material, way of expression, and musical shape).

The undertaking was applied within the form of a concert performance by students performers, who provided their own interpretations of famous works with the aid of Mussorgsky A walk, Jews, The Gnome, Baba Yaga. Their play turned into observed with the aid of a short poetic records and a visual cycle (listeners could simultaneously listen to track and consider the works of Hartmann, which stimulated the composer). The main semantic emphasis of the performer's interpretation changed into centered not on the "figurative" issue of the works, however on the embodiment of emotions and feelings via the musical sound.

\subsection{Features of Assessment of Knowledge and Skills Acquired During the Study of the Course Basic Musical Instrument (Piano)}

To check the formation of key know-how won all through the gap learning path fundamental Musical tool (piano), a number of exams were carried out inside the Moodle mastering environment.

Checking out of unique musical expertise, in addition to the level of capabilities of music perception, development of music listening abilities, reputation of musical works at some stage in listening was finished the usage of the take a look at service of the Moodle gaining knowledge of environment in versions: closed-ended project (pay attention to a piece of music and pick out the right solution many of the proposed ones); open-ended challenge (essay kind query: after listening to fragments of a musical composition it turned into important to answer in a positive column, indicating the author, the exact title of the work and segment, the act of the opera, a part of the symphony, topic, and many others.).

The effectiveness of the distance path delivered into the tools of the academic procedure of future tune teachers changed into analysed at the cease of the school year in the shape of an evaluation of the effectiveness of studying this path. Respondents have been divided into two groups: experimental group (27 college students) and manipulate organization (25 students). The experimental group labored inside the distance path primary Musical tool (piano) handiest. college students of the control institution participated in the study of the course using conventional methods and techniques. They attended character and organization classes on the principle musical device, ensemble and concertmaster training, and other classes in their typical curricula. instructions with students of the manage group were conducted the usage of traditional substances, with out the involvement of ICT and distance getting to know. The extent of motivational thing of future teachers of music and their capabilities were assessed throughout interviews.

Interviews had been carried out informally as part of the dialogue of the test, the results are presented in Figure 3. According to these effects, students of the experimental institution showed higher rates of hobby in learning and completing assignments. It changed into also noticed that the attendance of students of the experimental organization expanded by means of $12 \%$ compared to the manage institution.

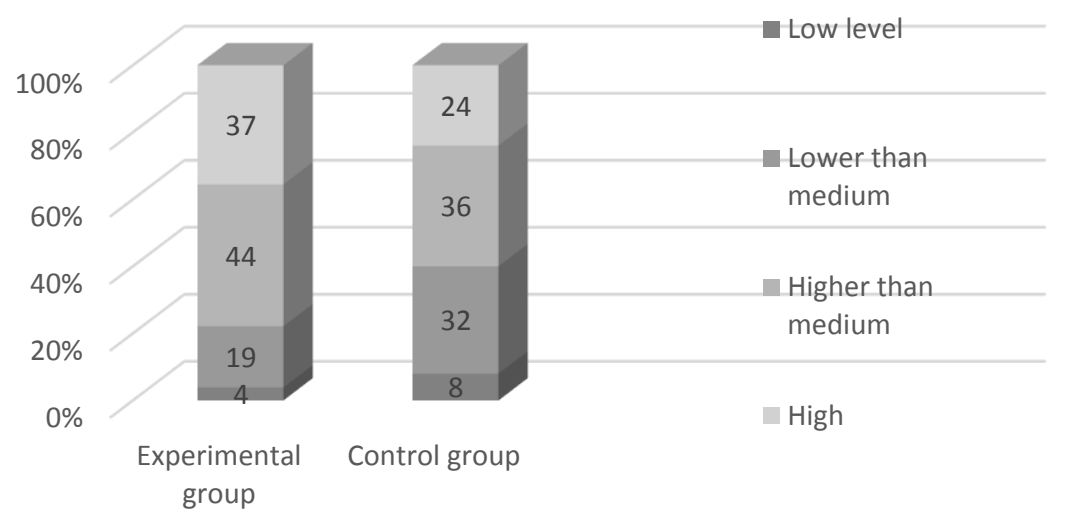

Figure 3. The level of motivational component of future music teachers in the aspect of musical instrumental competence 
Trying out applied within the Moodle digital getting to know surroundings turned into used to evaluate the cognitive abilties of future song instructors. The take a look at consequences presented in Figure 4 display that the educational experiment significantly stepped forward the expert word list of future music teachers.

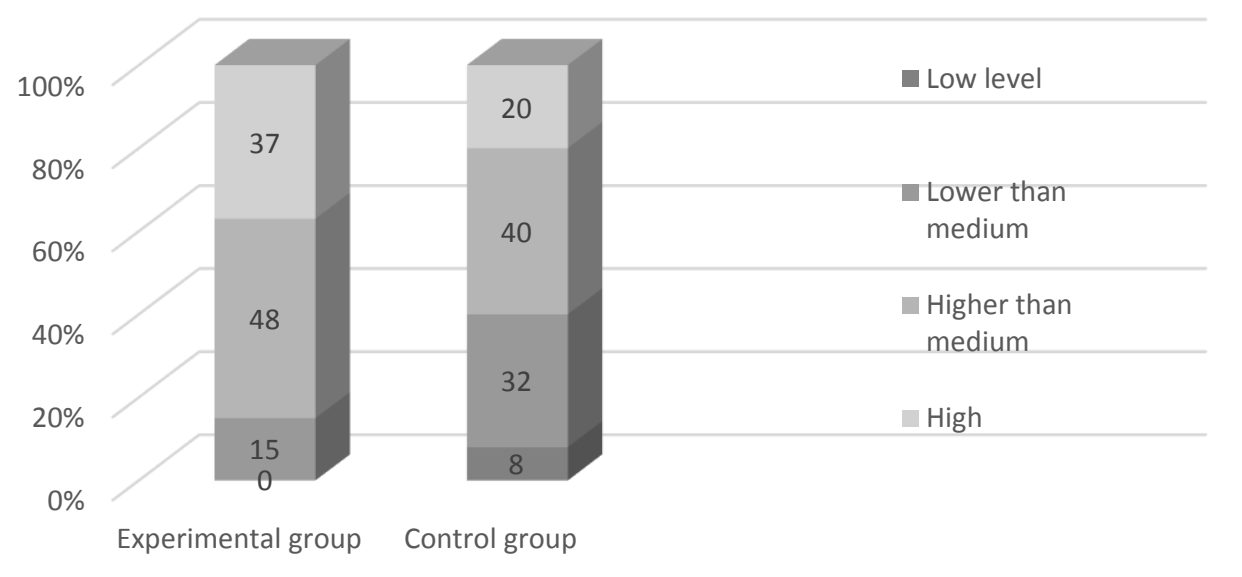

Figure 4. The level of the cognitive component of future music teachers in terms of musical instrumental competence

The level of the operational issue of future track which included verbal verbal exchange and musical teachers became assessed at the final examination, performance. The outcomes are offered in Figure 5.

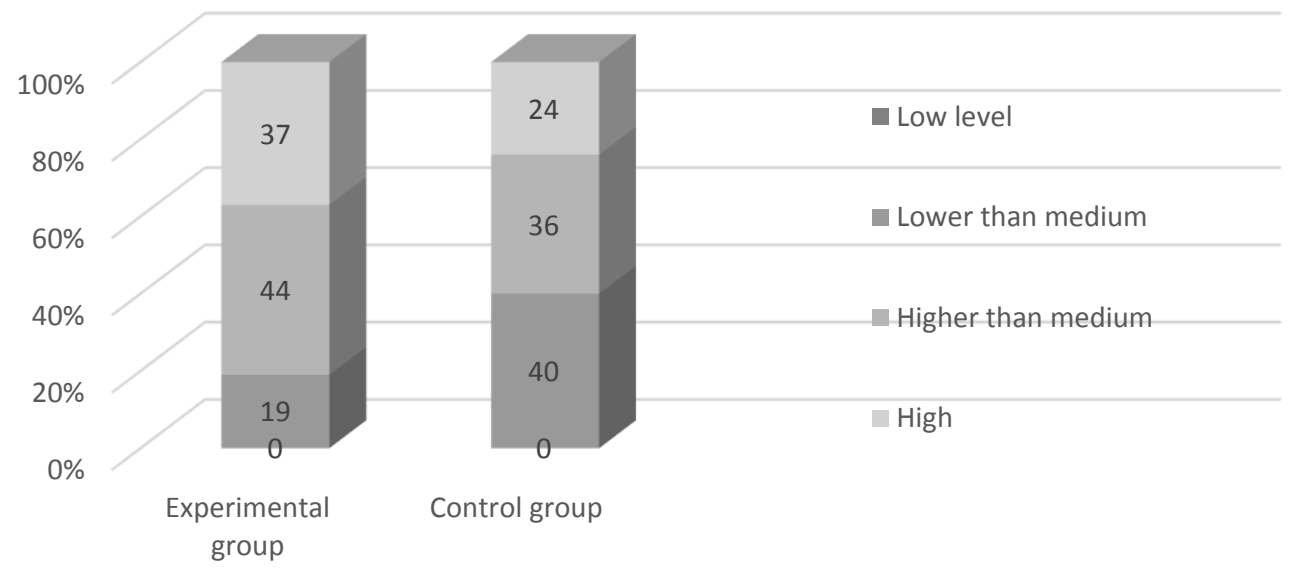

Figure 5. The level of operational component of future music teachers in terms of musical instrumental competence

In trendy, the effects of our have a look at reveal the effectiveness of the gap gaining knowledge of course primary Musical tool (piano) for similarly education of tune teachers, as the extent of 1 or any other issue of musical instrumental abilties within the experimental group turned into better than in the control one.

\section{Discussion}

Thus, the distance course Basic Musical Instrument (piano) provides individual lessons with students with the ability to adjust and adapt the content of these lessons in accordance with the abilities and prior musical training of students. The course is aimed at further development of previously acquired instrumental knowledge and skills, as well as to prepare students for the use of musical instruments in music lessons and extracurricular activities in comprehensive schools.

In the aspect of our research, we used a number of foreign works. Their methodology is close or similar to that used in this article. For example, the basis for our study was the method used by Swedish teachers. According to this method, joint research was organized by teachers and students of pedagogical faculties in order to update the content of the educational process of future music teachers. Joint research was based on the interview in focus groups [25].

This provided an opportunity both to accumulate and study the ideas expressed by particular students, and to form new ones in the process of discussions 
and dialogues among the group members. Participants in these focus groups became "coresearchers" on improving the learning process. In addition, focus group interviews were conducted during the educational process itself, and participants were informed that their opinions and judgments would not be evaluated, but the process of communication and generating ideas was important. The study involved two groups, each consisting of 15 students - future music teachers who were in their third year of study. The obtained data testified to the three most common types of ideas about music education among students: the first concerned the observations and impressions of students from music education at school; second their aspirations and thoughts on how to teach music; third - personal experience (before and after entering the speciality of music teacher) on how to teach music.

Compared to the above study, ours is more focused on the learning process itself, while almost not taking into account the opinion of students on the content and technical characteristics of the distance learning course Basic Musical Instrument (piano), which can be a promising vector of scientific research.

In addition, the results of Swedish research in the field of music education were also largely taken into account. However, it should be noted that back in 2010, these studies focused on the implementation and formation of democratic and inclusive ideals and goals in music education [25]. Therefore, the study of inclusive teaching methods in music pedagogy is an issue that can become a separate area of further research.

Given that the vast majority of European universities have integrated Moodle as a learning management system, our study, being directly related to the study of the implementation of distance learning methods, is based on the experience of integrating global pedagogy into information and communication technologies. This actually explains the topicality of our study, because compared to other educational content management systems, Moodle is an important and more effective tool in the didactic aspect [26].

To investigate the pedagogical impact of Moodle on learning, to understand, analyse and compare students' perceptions of the didactic features of Moodle in university teaching, Spanish researchers conducted a survey with a special sample of students from one of the Spanish higher education institutions [27].

They used a questionnaire consisting of 5 blocks and 118 variables to collect information. These surveys revealed the relevance of Moodle in university teaching: they noted a significant role that Moodle plays in visualizing the teaching context and for information exchange. In addition, students were mostly satisfied with distance learning through Moodle, although they were somewhat dissatisfied with the limitations related to teacher training and technical issues.

Similar studies were conducted using a similar method at the universities of Malaysia [28]. On a sample of 65 graduate students, they proved that the Moodle system is useful for the learning process. In particular, the media-interactive function of elearning can attract students' interest and attention to a particular course. In addition, e-learning tools are suitable for collaboration and knowledge exchange, and the use of certain options - for ecommerce, etc. In addition, Malaysian research shows a significant positive impact of the use of elearning systems on student learning motivation [28].

According to Latvian scholars, personalization has a great future in e-learning systems, especially open-source software such as Moodle [29]. Each user has their own skills, knowledge and individual characteristics, so to get positive learning outcomes, each user needs an individual approach, a personalized education system that will definitely be more useful than a unified one. In addition, this system must be able to assess the user's initial level of knowledge, ask him to study the missing data in his cognitive system, and take into account the learning progress. In this sense, our research needs to be detailed and deepened in terms of personalized learning and the development of individualized curricula.

\section{Conclusions and Recommendations for future research}

Competence formation is one of the precedence guidelines of education transformation. The potential to solve expert problems is fundamental for the development of expert competence in students of creative pedagogical specialties in standard and future teachers specifically.

The carried out studies allowed us to recognise ready studies goals, together with the ones related to solving professional issues. In particular, the space gaining knowledge of route basic Musical instrument (piano) evolved in accordance with the curricula became successfully applied in academic and pedagogical exercise, the usage of the Moodle mastering control system. This way of analyzing the path gave its high-quality results, specifically, in 
phrases of cognitive, operational (instrumental) and motivational components of the competence degree of destiny music teachers. The mission approach, which become extensively utilized in the path, is a justified detail of distance learning, as it promotes the formation of competencies to integrate students' efforts and skills to obtain common gaining knowledge of goals. The nice and speed of attaining these desires immediately impacts learning outcomes (instructional performance).

The exercise of the use of digital tests as a manipulate tool proves that they're extra appropriate for monitoring the cognitive thing of the talents of future music teachers.

The overall results of reading the space route primary Musical tool (piano) are a number of expert instrumental capabilities, which had been showed by means of more than $80 \%$ of students inside the experimental group. Especially, it's miles loose gambling a musical tool (piano), the capacity to use it in educational, concert and performing sports; studying sheet tune, transposing, choosing music by means of ear; mastered techniques of coaching to play musical units; ability to pick out instrumental music for students in song lessons and throughout extracurricular sports.

Hence, the implementation of the distance learning course basic Musical device (piano) in the gadget of training destiny song teachers permits drawing the following conclusions:

1. The paintings of students inside the distance getting to know path primary Musical tool (piano) should be combined with different coaching strategies, along with practice of gambling the piano and direct consultations. This mixture of forms and techniques of distance and traditional education looks like a combined version, rather than purely distance getting to know. This work lets in the trainer to begin to act as a representative, who accompanies and supervises the practical lessons amongst college students via e-gaining knowledge of and in step with the commands of the curriculum at the equal time.

2. Given the superb effects of the advent of distance studying courses in terms of music instrumental schooling of destiny song instructors, the prospects for similarly research encompass growing and the usage of new bureaucracy and strategies of distance gaining knowledge of: scribing, smartcards and comics as varieties of modern instructional infographics.

\section{References:}

[1]. Hartwig, K. A., Research Methodologies in Music Education. Cambridge Scholars Publishing, 2014.

[2]. Makhashova, P., On the development of professional competence in students of creative pedagogical specialities, International Journal of Environmental and Science Education, Vol. 11, No. 11, 2016, pp. 4660-4668.

[3]. Gromova, C. and Saitova, L., Pedagogical conditions of formation of professional competence of future music teachers on the basis of an interdisciplinary approach, International Journal of Environmental and Science Education, Vol. 11, No. 13, 2016, pp. 6162-6177.

[4]. Hollowell, J., Moodle as a Curriculum and Information Management System, Packt Publishing Ltd., 2011.

[5]. Ziraba, A., The adoption and use of Moodle learning management system in higher institutions of learning: a systematic literature review, American Journal of Online and Distance Learning, Vol. 2, No. 1, 2020, pp. 121. https://doi.org/10.47672/ajodl.489

[6]. Oproiu, G. C., A study about using e-learning platform (Moodle) in university teaching process, Procedia-Social and Behavioral Sciences, vol. 180, 2015, pp. 426-432.

[7]. Digolo, B. A., Andang'o E. A., Katuli, J., ELearning as a Strategy for Enhancing Access to Music Education, International Journal of Business and Social Science, Vol. 2, No. 11, 2011, pp. 135-139.

[8]. Iglesias-Pradas, S., Ruiz-de-Azcárate, C., Agudo-Peregrina, Á. F., Assessing the suitability of student interactions from Moodle data logs as predictors of cross-curricular competencies, Computers in Human Behavior, Vol. 47, No. C, 2015, pp. 81-89. https://doi.org/10.1016/j.chb.2014.09.065

[9]. Horvat, A., Student perception of Moodle learning management system: a satisfaction and significance analysis, Interactive Learning Environments, Vol. 23, No. 4, 2013, pp. 515527.

https://doi.org/10.1080/10494820.2013.788033

[10].Izzet, M., Applications of course management systems in school administration: Music teacher assessment through the use of digital portfolios, Doctoral dissertation, New York: St. John's University, School of Education and Human Services, 2013.

[11].Limongelli, C., Sciarrone, F., Vaste, G., Personalized e-learning in Moodle: the Moodle_LS System, Journal of e-Learning and 
Knowledge Society, Vol. 7, No. 1, 2011, pp. 4958. https://doi.org/10.20368/1971-8829/487

[12].Limongelli, C., A recommendation module to help teachers build courses through the Moodle Learning Management System, New Review of Hypermedia and Multimedia, Vol. 22, No. 1-2, 2016, pp. 58-82.

[13].Seluakumaran, K., Integrating an open-source course management system (Moodle) into the teaching of a first-year medical physiology course: a case study, Advances in Physiology Education, Vol. 35, No. 4, 2011, pp. 369-377.

[14].Zakaria, E. and Daud, M. Y., The role of technology: Moodle as a teaching tool in a graduate Mathematics Education course, Asian Journal of management sciences \& education, Vol. 2, No. 4, 2013, pp. 46-52.

[15].Alhothli, N. I., Investigating the impact of using Moodle as an e-learning tool for students in an English language institute. ScholarWorks at University of Montana, Graduate Student Theses, Dissertations, \& Professional Papers, 2015. Available online: https://scholarworks.umt.edu/etd/4524/ (accessed 27.06.2021).

[16].Wong, K., Teo, T. and Russo, S., Interactive whiteboard acceptance: Applicability of the UTAUT model to student teachers, Asia Pacific Education Researcher, Vol. 22, No. 1, 2013, pp. 1-10. http://dx.doi.org/10.1007/s40299-012$0001-9$

[17].Butova, A., Electronic Educational Environment Moodle in English Language Training, Arab World English Journal, Vol. 10, No. 1, 2019, pp. 47-55.

[18].Güsewell, A., Joliat, F. and Terrien, P., Professionalized music teacher education: Swiss and French students' expectations, International Journal of Music Education, Vol. 35, No. 4, 2017, pp. 526-540.

[19].Dwi Surjono, H., The Evaluation of a Moodle Based Adaptive e-Learning System, International Journal of Information and Education Technology, Vol. 4, No. 1, 2014 pp. 89-92.

[20].Fidalgo, P., Paz, J. and Santos, F. L., Using Moodle as a support tool for teaching in Higher Education in Portugal: an exploratory study, Eleed, Vol. 8, 2011. Available online: https://www.researchgate.net/publication/2603 00714 Using Moodle as a support tool for teaching_in_Higher_Education_in_Portugal_an exploratory_study (accessed 28.06.2021).

[21].Susana O., Improving graduate students learning through the use of Moodle,
Educational Research and Reviews, Vol. 10, No. 5, 2015, pp. 604-614.

[22].Wood, S. L., Technology for teaching and learning: Moodle as a tool for higher education, International journal of teaching and learning in higher education, Vol. 22, No. 3, 2010, pp. 299-307.

[23].Kiget, N. K., Wanyembi, G. and Peters, A. I., Evaluating usability of e-learning systems in universities, International Journal of Advanced Computer Science and Applications, Vol. 5, No. 8, 2014, pp. 97-102.

[24].Oye, N., Iahad, N. and Rabin, Z., A model of ICT acceptance and use for teachers in higher education institutions, International Journal of Computer Science \& Communication Networks, vol. 1, no. 1, 2011, pp. 21-40.

[25].Georgii-Hemming, E. and Westvall, M. Teaching music in our time: student music teachers' reflections on music education, teacher education and becoming a teacher, Music Education Research, Vol. 12, No. 4, 2010, pp. 353-367. https://doi.org/10.1080/14613808.2010.519380

[26].Moodle: Open-source learning platform. Available online: http://www.moodle.org (accessed 29.96.2021).

[27].Sánchez-Santamaría, J., Ramos-Pardo, F. J. and Sánchez-Antolín, P., The student's perspective: teaching usages of moodle at university, In L. Gómez Chova, A. López Martínez and I. Candel Torres (Eds.), Proceedings of ICERI 2012 conference, 19th-21st November 2012 (pp. 2968-2973), IATED, 2012.

[28].Raman, A., Usage of learning management system (Moodle) among postgraduate students: UTAUT model, Asian Social Science, Vol. 10, No. 14, 2014, pp. 186-192. https://doi.org/10.5539/ASS.V10N14P186

[29].Vagale, V., Personalization opportunities in the Moodle system, In D. Oḷehnovičs (Ed.), 53rd international scientific conference of Daugavpils University (pp. 293-296). Daugavpils, Daugavpils university academic supply "Saule", 2012.

\section{Creative Commons Attribution License 4.0 (Attribution 4.0 International, CC BY 4.0)}

This article is published under the terms of the Creative Commons Attribution License 4.0 https://creativecommons.org/licenses/by/4.0/deed.en_US 